\title{
Blemish Formation in Processed Microfilm
}

\author{
C. I. Pope \\ Institute for Basic Standards, National Bureau of Standards, Washington, D.C. 20234
}

(January 9, 1968)

\begin{abstract}
Oxidizing and reducing agents generated by paper cartons during storage may react with the image silver to form blemishes. The type of fixing bath, concentration of chlorine in the wash water, washing time and composition of the storage cartons can be factors that accelerate or retard the attack of the peroxide on the image silver. Microfilm washed after fixation in distilled water or chlorinefree tap water formed blemishes when exposed to peroxide paper. A trace of silver chloride in the image silver of processed microfilm augmented the formation of the natural type blemishes when exposed to peroxide paper, but high concentrations of residual silver chloride inhibited blemish formation. During storage, some storage cartons evolved formaldehyde, formic acid, and ammonia which created a chemical environment favorable for blemish formation in microfilm in the presence of peroxide. A correlation was found between the incidence of blemishes and the brand of paper storage cartons. A procedure was developed for testing processed microfilm to determine its susceptibility to blemish formation. According to the present theory, peroxide reacts with the silver in the image, forming colloidal silver which imparts a yellowish or reddish color to the blemishes.
\end{abstract}

Key Words: Archival record film, blemishes due to aging, colloidal silver, microfilm, microfilm storage cartons, permanent record film, peroxides.

\section{Introduction}

Blemish formation in stored microfilm has been under investigation for some time $\left[1,2,3 \mid .{ }^{1}\right.$ The nature of the problem and the types of blemish formation have been described $[1,2]$. It has been shown that oxidizing and reducing agents, probably peroxides, emitted by paper cartons in which the microfilm is stored attack the silver in the image, causing yellowish or reddish blemishes [4]. In the present study, the processing procedure was investigated to determine its effect on blemish formation. In this paper the term "blemish" includes various types of spots and edge attack on characters and other image boundaries.

\section{The Role of the Processing Procedure in Blemish Formation in Microfilm}

In the investigation of processing variables, four fine grain $16 \mathrm{~mm}$ microfilms, made by three manufacturers, were used. The processing solutions and times of developing, stopping, and fixing are given in the appendix. The microfilm samples were processed in beakers and agitated with a glass rod. The chlorine concentration of the wash water was determined by a Taylor chlorine analyzer [7] using the $o$-tolidene dihydrochloride reagent.

' Figures in brackets indicate the literature references at the end of this paper.
The peroxide source for testing the microfilm was a chromatographic paper, $0.03 \mathrm{~cm}$ thick, which had been treated in aqueous hydrogen peroxide. The test procedure is described in section 5 . From 2 to $4 \mathrm{~cm}^{2}$ of the peroxide paper formed spots in areas of microfilm containing natural spots. All microfilms were dried at least 1 day after processing or other treatment before exposure to peroxide paper.

\subsection{Effect of the Fixing Bath and Wash Water}

A study was made to determine if processed microfilm formed blemishes when the thiosulfate was removed by washing in chlorine-free water. The fixing baths tested were a neutral bath, a nonhardening acid bath, and an acid hardening bath. The wash waters were distilled water and chlorine-free tap water which had a $p \mathrm{H}$ of about 8 . Chlorine-free tap water was obtained by storing cold tap water until the chlorine disappeared or by adding sodium sulfite to the tap water to neutralize the chlorine. For a chlorine concentration of $1.2 \mathrm{ppm}, 50 \mathrm{ml}$ of a sodium sulfite solution containing $0.500 \mathrm{~g}$ per liter was sufficient for 4 liters of tap water. About $50-\mathrm{cm}$ lengths of the microfilms were exposed to a test pattern having various kinds of information, developed, fixed and washed in 1-liter baths of the wash water in 1.5-liter beakers. Three baths of the wash water were used for a 3-min wash and for longer washes a bath was used for each additional $5 \mathrm{~min}$ of washing. The sample was trans- 
ferred from beaker to beaker and agitated with a glass rod. The temperature of the processing solutions and wash water was $26^{\circ} \mathrm{C}$.

The processed microfilms developed spots and, in some cases, edge attack when exposed to peroxide paper. The microfilm fixed in the neutral and the nonhardening baths and washed in distilled water developed much larger spots than microfilm fixed in the nonhardening and the acid hardening baths and washed in chlorine-free tap water. The spots in the latter two fixing procedures were more numerous and had sharper edges than those for the first two fixing procedures with distilled water washing. The spots were almost contiguous to each other for microfilm fixed in the acid hardener bath. The spots from all fixing baths appeared white when they first developed but turned yellow or yellowish as the peroxide attack continued. The edges of the spots were slightly fuzzy. No significant differences were observed between blemishes formed after a 3-min wash and a 15-min wash.

The results of the tests are shown in table 1, where the observed effect for each processing procedure and the amount of peroxide paper necessary to induce blemish formation are indicated. The residual thiosulfate in the microfilm samples that formed blemishes ranged between 0 and $3 \mu \mathrm{g}$ per $6 \mathrm{~cm}^{2}$ of the image area. Microfilm D retained more residual thiosulfate than the other microfilms and exhibited only slight blemish formation for the neutral and the nonhardening baths and none for the acid hardening bath when washed in chlorine-free water. Microfilm A, fixed in the acid hardening bath and washed in distilled water, had a residual thiosulfate concentration of $10 \mu \mathrm{g}$ per $6 \mathrm{~cm}^{2}$, making it resistant to peroxide attack. The results show that microfilm developed blemishes when exposed to peroxide paper if the processing procedure was such that the residual thiosulfate was reduced to a very low level. A higher concentration of residual sodium thiosulfate would form additional silver sulfide in the image silver, protecting it from oxidation. The thiosulfate was more difficult to wash from the microfilm after fixation in the acid hardener bath than in the neutral or nonhardening acid bath, but chlorinefree tap water still removed the thiosulfate sufficiently to permit blemish formation. The tap water, being slightly alkaline, acted as a thiosulfate eliminator.

\subsection{Effect on Blemishes of Silver Chloride Formed in Microfilm by Chlorine in Tap Wash Water}

It was found that silver chloride formed in processed microfilm during processing is a factor in blemish formation. Trace amounts of silver chloride enhance blemish formation but larger concentrations inhibit it.

Water from city taps generally contains 0.1 to $1 \mathrm{ppm}$ of chlorine [8]. The chlorine in tap water forms hypochlorous acid (HOCl) which is a powerful oxidizing agent because it liberates oxygen $(\mathrm{HOCl} \rightarrow \mathrm{HCl}+\mathrm{O}$ ) [9]. The evolved oxygen oxidizes the silver in the image to silver ions which in turn combine with the ever-present chloride ions in tap water to form silver chloride.

Tests were made of the effect of chlorine in the wash water on blemish formation in microfilm A. The microfilm was fixed in an acid hardening bath. Samples were washed for $30 \mathrm{~min}$ in running tap water at $27^{\circ} \mathrm{C}$, containing $0.8 \mathrm{ppm}$ of chlorine in one run and $1.2 \mathrm{ppm}$ in a second run, and exposed, respectively, to $6 \mathrm{~cm}^{2}$ and $8 \mathrm{~cm}^{2}$ of the peroxide paper. No blemishes developed on the microfilm samples. Other samples were washed at $26{ }^{\circ} \mathrm{C}$ for a total of $30 \mathrm{~min}$ by placing them in a succession of tap water baths containing $0.3 \mathrm{ppm}$ of chlorine for $2,3,5,10$, and $10 \mathrm{~min}$, respectively. Exposure to $4 \mathrm{~cm}^{2}$ of peroxide paper produced some

TABLE 1. Blemish formation on exposure to peroxide paper for four microfilms and various processing procedures

Processing procedures

\begin{tabular}{|c|c|c|c|c|}
\hline Microfilm & $\begin{array}{l}\text { Neutral fix and washed } \\
\text { in distilled water for } \\
3 \mathrm{~min}\end{array}$ & $\begin{array}{l}\text { Nonhardening acid fix } \\
\text { and washed in distilled } \\
\text { water or chlorine-free } \\
\text { tap water for } 3 \mathrm{~min}\end{array}$ & $\begin{array}{l}\text { Acid hardening fix and } \\
\text { washed in chlorine-free } \\
\text { tap water for } 3 \mathrm{~min}\end{array}$ & $\begin{array}{l}\text { Acid hardening fix and } \\
\text { washed in distilled } \\
\text { water for } 40 \mathrm{~min}\end{array}$ \\
\hline A....... & $\begin{array}{l}\text { Many spots and edge } \\
\text { attack. }\end{array}$ & $\begin{array}{l}\text { Many spots and edge } \\
\text { attack. }\end{array}$ & $\begin{array}{l}\text { Many spots but no } \\
\text { edge attack. }\end{array}$ & No spots or edge attack. \\
\hline B....... & $\begin{array}{l}\text { Many spots and edge } \\
\text { attack. }\end{array}$ & $\begin{array}{l}\text { Many spots and edge } \\
\text { attack. }\end{array}$ & $\begin{array}{l}\text { Many spots but no } \\
\text { edge attack. }\end{array}$ & \\
\hline C.... & $\begin{array}{l}\text { Many spots and edge } \\
\text { attack. }\end{array}$ & $\begin{array}{l}\text { Many spots and edge } \\
\text { attack. }\end{array}$ & $\begin{array}{l}\text { Many spots but no } \\
\text { edge attack. }\end{array}$ & \\
\hline $\mathrm{D} \ldots \ldots \ldots$ & $\begin{array}{l}\text { Few spots but edge } \\
\text { attack. }\end{array}$ & $\begin{array}{l}\text { Few spots but edge } \\
\text { attack. }\end{array}$ & No spots or edge attack.. & \\
\hline $\begin{array}{l}\text { Amount of peroxide paper } \\
\text { used. }\end{array}$ & 1 to $2 \mathrm{~cm}^{2} \ldots$ & $2 \mathrm{~cm}^{2} \ldots$ & 4 to $8 \mathrm{~cm}^{2} \ldots$ & $8 \mathrm{~cm}^{2}$. \\
\hline
\end{tabular}


spots but a considerable resistance to blemish formation was noted when compared to samples washed in chlorine-free tap water.

After fixation, microfilm A was washed in running tap water at $27{ }^{\circ} \mathrm{C}$, containing $1.2 \mathrm{ppm}$ chlorine for $3,6,9,15$ and $30 \mathrm{~min}$. A sample was removed at the end of each washing time. The processed microfilm was exposed to $4 \mathrm{~cm}^{2}$ of the peroxide paper. The microfilm samples fixed in the acid hardening bath developed a high incidence of yellow spots for the 3 -min wash, a few in the 6-min wash, and none in the 9,15 , and 30-min washes. The microfilm samples fixed in the nonhardening bath developed many light yellow spots for the 3 -min wash, with slight yellowing of the image silver, a decrease in number of spots and no yellowing for the 6-min wash, a few spots for the 9-min wash, and none for the 15 and 30 -min washes.

Thus a high concentration of chlorine in the wash water formed silver chloride in the image silver making it resistant to yellowing and spot formation when exposed to peroxide. Furthermore, resistance to blemish formation increased with the washing time for $1.2 \mathrm{ppm}$ of chlorine in the tap wash water and 10 to 15 min was required to impart complete resistance. At the end of the 3-min wash, the thiosulfate had reached a low concentration and the chlorine began to form silver chloride. As the washing progressed, more silver chloride was formed and it finally reached a concentration which inhibited blemish formation. The spots which formed after fixation in the acid hardening bath and a 3 -min wash were more yellow than those obtained from the nonhardening bath and a 3-min wash. This would be the expected effect of acid carried over into the wash water from the acid bath, since chlorine reacts more rapidly in the presence of acid to form silver chloride. Since the tap water had a $p \mathrm{H}$ of about 8 , a high concentration of chlorine and a considerable washing time was necessary to form sufficient residual silver chloride to inhibit blemish formation. Tap water containing low concentrations of chlorine, such as $0.3 \mathrm{ppm}$, may not form a sufficient amount of silver chloride to inhibit blemish formation even after a 30 -min wash but the tests described above for $0.3 \mathrm{ppm}$ of chlorine in wash water showed that some resistance to blemish formation was obtained.

Microfilm containing sufficient silver chloride to make it resistant to blemish formation loses this resistance if treated for $10 \mathrm{~min}$ in a 0.2 percent solution of ammonium hydroxide to remove the silver chloride. Microfilm so treated showed only an even yellowing of the image silver when exposed to 2 to $4 \mathrm{~cm}^{2}$ of the peroxide paper.

It is not known how long silver chloride formed from chlorine in the tap water will impart resistance to blemish formation from peroxide attack. But in section 3 it is shown that chemicals given off by the storage cartons do react with the image silver, causing blemish formation in the presence of peroxide. Evidently the silver halide, if present, is partially reduced by the peroxide.

\subsection{Effect of lodide in the Fixer}

It has been shown [12] that the silver in a photographic image is partially sulfided during fixation. If iodide is added to the fixing bath most of the sulfiding is prevented, leaving a layer of silver iodide on the silver grains.

Henn, Wiest, and Mack [14] have reported that collections of microfilm processed in iodide-containing developers or fixing baths to be relatively free from blemishes. They recommend the use of $0.2 \mathrm{~g}$ of potassium iodide per liter of fixing solution to give microfilm greater resistance to blemish formation.

Tests were made on four microfilms by adding $0.2 \mathrm{~g}$ of potassium iodide to each liter of the acid hardening fixing solution. After development, the samples were fixed and washed in chlorine-free tap water. The chlorine-free tap water was used to avoid the blemish inhibiting effect of the chlorine. The samples were exposed to 2 to $8 \mathrm{~cm}^{2}$ of the peroxide paper. The microfilms showed more even yellowing of the image silver than the controls without iodide, indicating that iodide had made the image silver more susceptible to attack by peroxide. (If natural blemishes were caused by peroxide from the boxes, this finding seemed inconsistent with the field observations.) The resistance to spot formation was about the same as the controls. However, if the microfilms fixed with iodide in the fixer were washed in the chlorine-free tap water to which $1 \mathrm{ppm}$ of chlorine was added, they, like the controls, resisted blemish formation and did not show an even yellowing. Old microfilms which had been processed with iodide in the fixing bath formed blemishes when exposed to peroxide at low levels of 2 to $4 \mathrm{~cm}^{2}$ of the peroxide paper.

To simulate actual practice, a study was then made of the effect of storing processed microfilm in fresh storage cartons. The films in cartons were placed in a desiccator jar for 10 days at 86 percent relative humidity and $26^{\circ} \mathrm{C}$ and then the samples were exposed to 2 to $4 \mathrm{~cm}^{2}$ of the peroxide paper. The samples processed with potassium iodide in the fixer developed a few blemishes but samples processed without potassium iodide in the fixer developed many more. These tests confirmed the field observations and suggested that chemicals in addition to peroxide were generated in the storage carton and played a part in the chemistry of blemish formation.

\subsection{Natural-Type Blemishes Obtained With Acid and Silver Chloride in the Image}

A small amount of silver chloride was formed in the image silver of old films and freshly processed films. When these films were exposed to peroxide, sharpedged blemishes formed which resembled very closely those found in nature, even duplicating the ring formation and edge attack. The films were exposed to about $25 \mathrm{~cm}^{2}$ of the peroxide paper at 76 percent relative humidity and $26{ }^{\circ} \mathrm{C}$. A higher relative 
humidity did not produce the natural-type blemishes. Although these tests may not be applicable to microfilm as normally processed and stored they do suggest that a trace of silver chloride contributes to blemish formation under natural storage conditions.

For these experiments, processed films were treated $10 \mathrm{~min}$ in a solution containing $0.025 \mathrm{~g}$ of sodium chloride and $3 \mathrm{ml}$ of glacial acetic acid per liter, dried and exposed to peroxide paper. (Formic acid may be substituted for the acetic acid.) The $0.025 \mathrm{~g}$ of sodium chloride per liter gave a solution containing $15 \mathrm{ppm}$ of the chloride ion which is close to the median value of $13 \mathrm{ppm}$ in the water supplies of large cities [6]. The oxygen dissolved in the sodium chloride-acetic acid solution oxidized the image silver to silver ion which combined with the chloride ion to precipitate silver chloride in the image silver. The silver chloride formed in microfilm by the sodium chloride-acetic acid solution may be removed by treating the film for $10 \mathrm{~min}$ in a 0.2 percent solution of ammonium hydroxide. After such treatment, the image silver showed only an even yellowing after exposure to peroxide paper. When microfilm was treated in a solution of $3 \mathrm{ml}$ of acetic acid per liter without the sodium chloride and exposed to peroxide paper, no spot or edge blemishes formed in the image silver, only an even yellowing.

The microfilms A, B, C and D, reported in section 2.1 , which readily formed blemishes when exposed to peroxide paper were treated in the sodium chlorideacetic acid solution and dried. Peroxide exposure produced natural type spots, some with ring structure, and edge attack. There was no even yellowing, indicating that silver chloride was formed throughout the image. The edges of the spots were sharp and the spots were deep yellow, showing the effect of silver chloride. The number of spots was much less than before the sodium chloride-acetic acid treatment since too much silver chloride had been formed at most points in the image for spot induction.

Blemish formation was induced in old processed microfilms by treatment in chlorine gas or an acid solution of chlorine and subsequent exposure to peroxide. The films were exposed to chlorine gas by suspending the samples over a chlorine solution in a 1-liter closed glass bottle. The chlorine solution was prepared by dissolving $0.250 \mathrm{~g}$ of technical grade calcium hypochlorite containing 70 percent calcium hypochlorite in 1 liter of water and adding $5 \mathrm{ml}$ of glacial acetic acid. Approximately $400 \mathrm{ml}$ of this solution was added to the bottle. The film samples were soaked in distilled water for $10 \mathrm{~s}$, squeegeed with a dry glass rod and suspended immediately in the chlorine gas above the solution for 20 to $60 \mathrm{~s}$, dried overnight and exposed to peroxide paper. This method produced spot and edge attack but each brand of microfilm required a different time of exposure to the chlorine gas.

To determine whether silver chloride was formed in the image silver by the chlorine gas, microfilm samples were treated in a 0.2 percent ammonium hydroxide solution for $5 \mathrm{~min}$ to remove any existing silver chloride, dried overnight, treated $10 \mathrm{~s}$ in dis- tilled water, squeegeed, treated to the chlorine gas for $30 \mathrm{~s}$ and exposed to peroxide paper. These films had spot and edge attack.

Microfilm samples were immersed for $5 \mathrm{~s}$ in the chlorine solution described above, dried and exposed to peroxide paper. These microfilms showed spot and edge attack but were more resistant to peroxide because more silver chloride had been formed in the image silver.

The findings with respect to chlorine and chloride ion raised a question about the effects of the other halides, silver bromide and silver iodide. Old processed microfilm samples, blemish free, were treated $10 \mathrm{~min}$ in solutions of sodium bromide containing $0.045 \mathrm{~g} / \mathrm{l}$ and $3 \mathrm{ml}$ of glacial acetic acid, and potassium iodide containing $0.060 \mathrm{~g} / \mathrm{l}$ and $3 \mathrm{ml}$ glacial acetic acid. Strong spot and edge attack were obtained in most samples when exposed to peroxide paper. The amount of blemish formation decreased as the solubility of the corresponding silver halides decreased.

A method was developed for estimating the free silver in processed microfilm. "Free silver" as here defined includes silver ion, silver oxide and silver halides but the method does not show how much of the silver is in the form of halide salt. This method indicated as much free silver present in old processed microfilm which had been treated in a solution containing $3 \mathrm{ml}$ of acetic acid per liter as in microfilm treated in a solution containing $3 \mathrm{ml}$ of acetic acid and $0.025 \mathrm{~g}$ of sodium chloride per liter. However, when they were exposed to peroxide paper, the samples given the acetic acid and sodium chloride treatment resisted background yellowing though they had natural-like spots and edge attack while those given the acetic acid treatment showed only an even yellowing of the image silver. Apparently traces of silver in the image are oxidized by oxygen dissolved in the water, in the presence of acid, and if the chloride ion is present, silver chloride is formed.

The procedure for determining the free silver is outlined as follows. The free silver was extracted from $12 \mathrm{~cm}^{2}$ of processed microfilm with $10 \mathrm{ml}$ of a 0.2 percent solution of ammonium hydroxide containing $1 \mathrm{~g}$ of sodium chloride per liter. Two $6 \mathrm{~cm}^{2}$ pieces of microfilm were cut, folded emulsion in and placed back to back in a glass vial containing the test solution and allowed to stand $15 \mathrm{~min}$. The samples were removed by a glass rod having a hook at one end and $0.10 \mathrm{ml}$ of a potassium bromide solution containing $100 \mathrm{~g} / \mathrm{l}$ was added and mixed. Then the solution was acidified by adding $1 \mathrm{ml}$ of concentrated nitric acid diluted 1 to 5 and mixed, allowed to stand $\mathrm{l} \mathrm{hr}$ and the turbidity measured with a nephelometer. A calibration curve was prepared from known amounts of silver added to the standard solution as silver nitrate. One-fourth microgram of silver as silver nitrate gave a measurable turbidity. The values obtained are relative but were helpful in showing changes in the free silver content of microfilm after various treatments. The free silver content of old processed microfilms containing blemishes ranged from 0.2 to $1 \mu \mathrm{g}$ for $6 \mathrm{~cm}^{2}$ of film. 


\section{Formaldehyde, Formic Acid, and Ammonia From Paper Cartons}

Microfilms in which blemishes had formed during natural storage were studied to determine if more blemishes would develop in the laboratory peroxide test. Several rolls of microfilm having blemishes on the outer convolutions but none on the remainder of the roll were tested. Samples taken from blemish-free areas were tested and no blemishes developed, but samples from areas where blemishes had formed during storage did develop blemishes like those already present. The blemishes present before the test were ringed with a stylus to differentiate them from blemishes produced by the peroxide. Evidently chemicals in addition to peroxide had evolved from the paper carton during storage and created a chemical environment conducive to blemish formation in the presence of peroxide.

Formaldehyde, formic acid, and ammonia have been detected in the atmosphere within many of the paper storage cartons when stored at 100 percent relative humidity at $26^{\circ} \mathrm{C}$. A glass petri dish, $60 \mathrm{~mm}$ in diameter and $13 \mathrm{~mm}$ high, containing $10 \mathrm{ml}$ of distilled water was placed in the paper carton to absorb evolved chemicals. The carton was stored in a desiccator jar containing $25 \mathrm{ml}$ of distilled water for 1 to 3 days, one day being generally sufficient. This extraction procedure was used in testing for the presence of formaldehyde, formic acid, and ammonia. Formaldehydeurea and formaldyhyde-melamine resins have been widely used as wet-strengthening agents in paper manufacture for over 20 years. The chemicals detected were probably formed by hydrolysis of these resins at high relative humidities.

\subsection{Defection of Formaldehyde, Formic Acid, and Ammonia}

\section{a. Formaldehyde}

Two $\mathrm{ml}$ of the water solution which had been stored in the paper carton were added to $5 \mathrm{ml}$ of a 1 percent solution of chromotropic acid (4,5-dihydroxy, 2,7naphthalene disulfonic acid ${ }^{2}$ ) in concentrated sulfuric acid. Chromotropic acid readily detects formaldehyde in concentrations of $1 \mathrm{ppm}$ (15). Chromotropic acid gave a pink to dark purple color, a positive test for formaldehyde. The less sensitive resorcinol test gave a positive indication of formaldehyde from some cartons when the same water solution was stored successively in 3 cartons for a period of 3 days each. This test was made by adding $0.1 \mathrm{ml}$ of 1 percent solution of resorcinol to $5 \mathrm{ml}$ of the water solution and pouring the mixture carefully down the side of a test tube containing $5 \mathrm{ml}$ of concentrated sulfuric acid to form two layers. A pink color formed at the junction of the two layers. The formaldehyde was also identified by microwave absorption analysis. ${ }^{2}$ Obtained from Matheson Coleman and Bell, Cat. No. P5425, East Rutherford, New
Jersey.

\section{b. Formic Acid}

The water stored in the paper cartons had a $p \mathrm{H}$ range of 3.5 to 4.5 after storage for 3 days at 100 percent relative humidity at $26^{\circ} \mathrm{C}$. Titration with 0.001 $N$ sodium hydroxide solution indicated that the water stored in the cartons was about $0.001 N$ with respect to formic acid for some storage cartons. The water stored in the cartons decolorized a light pink solution of potassium permanganate, indicating that formic acid was present. When $5 \mathrm{ml}$ of the water solution was added to $5 \mathrm{ml}$ of saturated mercuric chloride and warmed in hot tap water for $10 \mathrm{~min}$, a precipitate formed, indicating reduction of the mercuric chloride. This test indicated the presence of formic acid. A precipitate of reduced silver formed when $2 \mathrm{ml}$ of silver nitrate solution containing $10 \mathrm{~g}$ per liter were added to $10 \mathrm{ml}$ of the water solution from the paper cartons and warmed $15 \mathrm{~min}$ in hot tap water. The reduced silver indicated the presence of formic acid which is capable of reducing the silver ion. This procedure detected $5 \mathrm{ppm}$ of formic acid in a known solution. The formic acid is evidently formed by oxidation of the formaldehyde by the peroxide generated in the storage cartons and possibly by aerial oxidation of formaldehyde, catalyzed by the silver in the image. A water solution of formaldehyde was found to increase in acidity when stored over silver dust for $4 \mathrm{hr}$ showing that formic acid was formed by the oxidation of formaldehyde.

\section{c. Ammonia}

About $10 \mathrm{ml}$ of the water stored in the paper cartons were placed in a $50-\mathrm{ml}$ beaker and made alkaline with sodium hydroxide. The beaker was covered with a watch glass having a strip of moistened red litmus paper attached to the underside and the beaker was warmed in hot tap water. After 30 to $60 \mathrm{~min}$ the litmus paper turned blue suggesting the presence of ammonia. A control test run on the distilled water was negative.

\subsection{Tests of Old and New Storage Cartons}

Some new storage cartons readily evolved formaldehyde when stored for $3 \mathrm{hr}$ in the drawer of a metal laboratory desk. A strong indication of formaldehyde was obtained after a new carton was stored at 100 percent relative humidity at $3{ }^{\circ} \mathrm{C}$ for 1 day, indicating that a low temperature does not stop the evolution of formaldehyde if the relative humidity is high. Most of the old storage cartons tested evidenced formic acid evolution.

Storage cartons from one collection of blemish-free microfilms evolved no formaldehyde or only a very small amount. Cartons from a second collection where blemishes have not been found evolved an appreciable amount of formaldehyde, but this collection is located in an arid climate which would minimize the evolution of formaldehyde and the formation of formic acid. All the tests of paper storage cartons from collections where blemishes have been found, even collections that were ten years old, gave a strong indication of formaldehyde. 


\subsection{Reactions of Formaldehyde, Formic Acid, and} Ammonia on Silver and Gelatin

During natural storage, blemishes generally form on the outside leader and edges of the microfilm roll, which are the areas most accessible to gaseous chemicals evolved by the storage carton. Formaldehyde will harden gelatin by reacting with the amino groups attached to the amino acids in the gelatin. Blemish formation was inhibited in a blemish forming microfilm after an exposure of $24 \mathrm{hr}$ to the gaseous phase of a 2 percent solution of formaldehyde. This severe test may not be relevant to natural storage conditions but suggests that formaldehyde, alone, may inhibit blemish formation. Formaldehyde and formic acid neutralize the alkalinity of the amino groups making the gelatin more acidic.

Formic acid and chloride ion reacted with the image silver at high relative humidities to form silver chloride in the same manner as described in section 2.4 for the sodium chloride-acetic acid solution, making the high-density uniform image more resistant and the edges of the blemishes sharp, when the film was exposed to peroxide evolved by the storage cartons.

In section 2.2 it was noted that tap wash water having as much as $1 \mathrm{ppm}$ of chlorine formed a sufficient amount of silver chloride in the microfilm to make it resistant to blemish formation. The formic acid from cartons stored at high relative humidities appears capable of reducing the silver chloride concentration to a level favorable for blemish formation. Formic acid readily reduced the silver ion in an aqueous solution of silver nitrate, forming a gray precipitate of silver. Solid silver chloride in a solution of formic acid turned slightly gray after standing in the dark for 7 days. A control without formic acid did not exhibit this effect. The gray color was attributed to reduced silver.

Experiments were performed to see whether or not residual silver chloride in the image silver of processed microfilm is susceptible to reduction by formic acid and peroxide. To incorporate silver chloride into clear (image-free) processed microfilm, the film was washed $20 \mathrm{~min}$ in distilled water, treated $10 \mathrm{~min}$ in a solution containing $5 \mathrm{~g}$ of silver nitrate per liter, treated $10 \mathrm{~min}$ in a second solution containing $5 \mathrm{~g}$ sodium chloride per liter, washed $20 \mathrm{~min}$ in distilled water and dried. When exposed to $24 \mathrm{~cm}^{2}$ of paper treated with formic acid, samples of this microfilm developed a yellow color in the gelatin layer, indicating reduction of the silver chloride. The test was made at 86 percent relative humidity and $26{ }^{\circ} \mathrm{C}$ and in the same type of desiccator jar used for peroxide tests. The paper was prepared by treating Whatman No. 3MM filter paper in a 10 percent formic acid solution for $30 \mathrm{~min}$ drying it $3 \mathrm{hr}$ at $26^{\circ} \mathrm{C}$ and storing it at approximately $-10{ }^{\circ} \mathrm{C}$. Microfilm placed in a new storage carton for 12 days at 86 percent relative humidity and $26^{\circ} \mathrm{C}$ showed evidence of reduction of silver chloride. Samples exposed to $6 \mathrm{~cm}^{2}$ of the peroxide paper also evidenced such reduction. Thus residual silver chloride reduction in stored microfilm should decrease the blemish resistance.
It was found that the silver-chloride-ammonia complex was more easily reduced by formic acid and peroxide than silver chloride precipitated in the gelatin layer as described above. Tests were made on clear (image-free) processed microfilm treated $5 \mathrm{~min}$ in a solution containing $0.5 \mathrm{~g}$ of silver chloride dissolved in one liter of water containing $8 \mathrm{ml}$ of concentrated ammonium hydroxide. The results indicated that ammonia evolved by storage cartons may make the silver chloride more sensitive to reduction by formic acid and peroxide.

The above data shows how microfilm resistant to blemish formation when stored may lose its resistance to peroxide in the presence of other chemicals evolved by the paper storage carton. Although both peroxide and formic acid reduce silver chloride, formic acid may be the principal reducer since blemishes have generally been found in microfilm stored in paper cartons which evolve relatively large amounts of formaldehyde and formic acid.

\section{The Chemistry of the Formation of Blemishes in Processed Microfilm}

\subsection{Theory}

Paper cartons in which microfilm is stored undergo degradation at high relative humidity and high temperature to form peroxide. The silver in the image serves as a catalyst to decompose the peroxide, forming oxygen which oxidizes the image silver to the silver ion. The chloride ion catalyzes the oxidation of silver by peroxide. The peroxide [11] and formic acid reduce the silver ion to yellow colloidal silver.

Processed microfilms exposed for 2 min to the gas phase of 20-percent hydrochloric acid formed spot blemishes when exposed to peroxide paper. The hydrochloric acid reacted with the image silver to form silver chloride [10]. Many white spots formed, a few with a sharp ring structure, but they were colorless because the gelatin was too acid for the formation of the yellow to red colloidal silver found in naturally occurring spots. Under these conditions only oxidation of the silver occurred but concomitant oxidation and reduction must occur to form yellow to red colloidal silver. When the samples with the white spots were given a printout exposure and treated in a developer solution the spots were still colorless. This indicated that the silver ion had not remained in the colorless area but had migrated to the edge of the spots.

The silver ion may be reduced in an aqueous solution to form colloidal silver [9]. The reduction of silver ion in the gelatin layer of processed film by peroxide forms yellow colloidal silver. A proprietary product containing 19 to 23 percent silver in the colloidal state in gelatin is known in the trade as "Solargentum" [13]. Processed microfilm having no silver image was washed in distilled water, treated in a dilute solution of silver nitrate or silver acetate and dried. When samples were exposed to peroxide at 86 percent relative humidity and $26{ }^{\circ} \mathrm{C}$, the gelatin layer turned yellow. Reducing agents evolved by paper storage 
cartons formed the same yellow color in the gelatin of other samples stored in the cartons for 10 days at 86 percent relative humidity and $26^{\circ} \mathrm{C}$.

There is another type of colloidal silver formed when ionic silver is reduced in the presence of an insoluble silver salt such as silver chloride. This type of colloidal silver appears to be silver dispersed in a silver halide and gives colors ranging from pink, red, yellow, brown to gray when formed in an aqueous solution but yellow or reddish when formed in the gelatin layer of microfilm. Carey Lea claimed that this colloid was a mixture of silver chloride and a subhalide of silver. Mees [5] has pointed out that it may be regarded as a mixture of silver in silver halide.

Tests showed that the blemishes contained ionic silver in addition to colloidal silver. The black specks in the centers of many spots appear to be reduced silver since they are readily dissolved by strong nitric acid. In section 2 it was noted that large spots, with light yellowing and even attack on the image silver, were obtained when the microfilm was fixed in a neutral fixer or a nonhardening fixer and washed in distilled water. In these processing procedures no chloride or bromide ions should be present to form silver halide and the yellow color would be attributed to the silver-gelatinate type of colloidal silver. However, when the microfilm was fixed in the nonhardening fix or the acid-hardening fix and washed in chlorinefree tap water the spots were sharper, more yellow, attended by no edge attack or even attack on the image silver, and required more peroxide for spot formation. The chloride ion introduced by the tap water formed silver chloride which led to the formation of the silver-silver chloride type of colloidal silver in spots and prevention of even attack on the image silver. The silver-silver chloride colloidal silver probably predominates in blemish formation.

\subsection{Formation of Silver-Silver Halide Colloidal Silver in Solution and on Silver Strips}

It was found possible to form the silver-silver chloride type of colloidal silver in water solution. Thirty percent hydrogen peroxide was added to a solution containing varying concentrations of sodium chloride in the presence of solid silver oxide. A small amount of silver oxide dissolved making the solution alkaline. Reduced gray silver accumulated in the bottom of the beaker, leaving the solution clear when no chloride ion was present. When chloride ion was added, a colloidal suspension formed, ranging in color from pink to yellow and sometimes a reddish precipitate formed along with the gray reduced silver. Treatment of the reaction mixture with nitric acid dissolved the reduced silver and left a yellow or reddish colloidal suspension and a reddish precipitate. The pink, yellow and reddish color in the colloidal suspension resembled the color of natural spots. The optimum condition for producing the colloidal silver was a $60-\mathrm{ml}$ solution containing $0.05 \mathrm{~g}$ of sodium chloride and about 0.5 to $1 \mathrm{~g}$ of solid silver oxide. The hydrogen peroxide was added dropwise with stirring.
Equal mol concentrations of potassium bromide $(0.102 \mathrm{~g})$ and potassium iodide $(0.142 \mathrm{~g})$ equivalent to $0.05 \mathrm{~g}$ of sodium chloride were used in the above procedure to test for the formation of colloidal silver. The potassium bromide solution produced a light yellowish colloidal suspension with a trace of reddish color and some reddish precipitate. The potassium iodide solution gave no visual evidence of the formation of colloidal silver in the solution although a faint trace may have been present. A small amount of sodium chloride in the potassium iodide solution did produce a slightly yellowish colloidal solution indicating that colloidal silver will form in the presence of potassium iodide and the chloride ion.

The silver-silver chloride type of colloidal silver was also formed on silver strips. The silver strips were cleaned with nitric acid, washed in distilled water and immediately immersed in a $50-\mathrm{ml}$ solution containing $0.05 \mathrm{~g}$ of sodium chloride, to which 30 percent hydrogen peroxide was added dropwise. A heavy reddish coating of colloidal silver formed on the silver strip showing that the silver on the strip was both oxidized and reduced by the peroxide. When no sodium chloride was added, the silver strip remained bright and served only as a catalyst to decompose the peroxide into water and oxygen. There was no precipitate of reduced silver. These results showed that the chloride ion played an important part in the oxidation of the silver by the peroxide.

\section{Test for the Formation of Blemishes in Processed Microfilm With Peroxide Paper}

\subsection{Preparation of the Peroxide Paper}

It was found that paper treated in a solution of hydrogen peroxide was a good source of gaseous peroxide for the formation of blemishes in processed microfilm. All of the types of blemishes described in NBS Handbook 96 [2] have been produced by exposing films to such paper. The paper used was Whatman No. 3MM filter paper which is used in chromatography. The paper was treated $30 \mathrm{~min}$ in a 5 -percent solution of hydrogen peroxide at room temperature with occasional stirring, hung in a ventilating hood for $2 \mathrm{hr}$, dried for $24 \mathrm{hr}$ in a desiccator over anhydrous calcium sulfate at $26^{\circ} \mathrm{C}$ and stored in a sealed glass bottle in a refrigerator at $-10{ }^{\circ} \mathrm{C}$.

\subsection{Apparatus}

The tests were made in a desiccator jar containing a saturated salt solution to control the relative humidity. The jar had an inside diameter of $160 \mathrm{~mm}$ at the ground flange and a volume of approximately $2300 \mathrm{ml}$. The air and salt solution were not stirred but the relative humidity value reported is that recorded in the literature for equilibrium conditions. The jar was covered with a flat glass plate about $0.6 \mathrm{~cm}$ thick and sealed with petroleum jelly. A porcelain plate perforated with small holes was located just above the saturated salt 
solution. Saturated solutions of sodium chloride and potassium chloride were used to obtain relative humidities of about 76 and 86 percent, respectively, at $26^{\circ} \mathrm{C}$.

The test samples, about $6 \mathrm{~cm}$ in length, were fastened at each end with black photographic masking tape to a thin glass plate about $8 \times 10 \mathrm{~cm}$ in size. Four or five samples could be mounted on a plate. The glass plate was then fastened at two opposite edges to the underside of the cover with a strip of the tape, so that the emulsion faced downward. A glass dish, $60 \mathrm{~mm}$ in diameter and $13 \mathrm{~mm}$ high, was centered in the middle of the porcelain plate to hold the peroxide paper. The mounted microfilm samples were about $8.5 \mathrm{~cm}$ from the peroxide paper. In testing microfilms for blemish formation the peroxide paper was added to the glass dish and allowed to react $24 \mathrm{hr}$ at $26^{\circ} \pm 1{ }^{\circ} \mathrm{C}$. Two $\mathrm{cm}^{2}$ of peroxide paper was sufficient for some microfilms. If no blemishes formed, $2 \mathrm{~cm}^{2}$ more of peroxide paper was added and the test was continued. Most of the blemish forming microfilms required 2 to $4 \mathrm{~cm}^{2}$ of the peroxide paper.

\section{Summary}

Microfilms fixed in a neutral or nonhardening acid bath and washed in distilled water or chlorine-free tap water, formed blemishes when exposed to peroxide paper. Microfilms fixed in an acid hardening bath and washed in chlorine-free tap water, also formed blemishes when exposed to peroxide paper but no blemishes formed after washing in distilled water. The distilled water wash did not reduce the concentration of the residual thiosulfate in the microfilm sufficiently to permit blemish formation. The silver sulfide formed in microfilm during fixation affords some protection against oxidation of the image silver by peroxide but its concentration is not large enough to prevent oxidation of the silver after washing in chlorine-free tap water. Residual thiosulfate reacts with the image silver in processed microfilm to form additional silver sulfide, giving a greater resistance to peroxide attack. Tap wash water containing a chlorine concentration of $1 \mathrm{ppm}$ formed a sufflcient amount of silver chloride in the image silver to make microfilm resistant to blemish formation when exposed to peroxide paper. One microfilm required a 10 -min wash after fixing in a nonhardening acid bath to inhibit blemish formation. The resistance to blemish formation by the silver chloride in the image silver can be removed by treating the processed microfilm in a 0.2 percent solution of ammonium hydroxide. The image silver showed an even yellowing after this treatment and exposure to peroxide paper. Some resistance to blemish formation was found when microfilms were washed $30 \mathrm{~min}$ in tap water containing a chlorine concentration of $0.3 \mathrm{ppm}$. A trace of silver chloride in the image silver promoted blemish formation. Thus the type of fixing bath, concentration of the chlorine in the wash water, and the washing time after fixation can be factors in the formation of blemishes in processed microfilm stored in paper cartons.

Formaldehyde-urea and formaldehyde-melamine type resins are incorporated in microfilm paper storage car- tons as wet-strengthening agents. These resins hydrolyze at high relative humidity to give formaldehyde and ammonia. Formic acid may form by the oxidation of the formaldehyde by the peroxide evolved by the storage carton and aerial oxygen in the presence of silver in the image. Microfilm containing sufficient residual silver chloride to prevent blemish formation loses this resistance when exposed to formic acid evolved in storage cartons. It was found that formic acid was capable of reducing silver chloride and the silver chloride ammonia complex in the gelatin layer of microfilm. The silver chloride ammonia complex was more easily reduced than silver chloride, suggesting that ammonia evolved by storage cartons may sensitize the reduction of the silver chloride in the image silver. A correlation has been found between the incidence of blemishes and the brand of storage cartons. Heavy blemish formation was found on a collection of $35 \mathrm{~mm}$ step tablets stored with paper sheets for 4 years in a desk drawer in this laboratory. These films had been washed 30 to $45 \mathrm{~min}$ in running tap water. The paper sheets were found to evolve formaldehyde and formic acid after 4 years in storage. These results show that chemicals evolved by paper cartons during storage may react with the image silver to form blemishes.

Microfilms fixed in a bath containing iodide ion formed blemishes when exposed to peroxide paper. However, the microfilms showed good resistance to blemish formation after storage in some paper cartons at 86 percent relative humidity. The same microfilms fixed in a bath without iodide showed appreciable blemish formation. The residual silver iodide in the image made the film resistant to attack by chemicals evolved by the storage cartons. These results are consistent with the finding of a lower incidence of blemish formation in stored microfilm containing iodide.

The present theory is that peroxide oxidizes the silver in the image and also reduces the silver ion. The reduced silver may form colloidal silver of the silver-gelatinate type or combine with a silver halide, forming the silver-silver halide type of coloidal silver.

\section{Appendix. Formulas for Developing and Fixing the Silver Image in Microfilm}

\subsection{Developer}

Monomethyl $p$-aminophenol sulfate.......... $2.0 \mathrm{~g}$. Sodium sulfite, anhydrous.................... $90.0 \mathrm{~g}$. Hydroquinone ............................... 8.0 g. Sodium carbonate, monohydrate............ 52.5 g. Potassium bromide............................ 5.0 g. Water to make.............................. 1 liter. The development time was $3 \mathrm{~min}$.

\subsection{Stop Baths}

No. 1 for Neutral Fixing Bath:

Treated sample $1 \mathrm{~min}$ in each of two 2-liter lots of distilled water. 
No. 2 for Nonhardening Acid Fixing Bath:

Sodium bisulfite $60.0 \mathrm{~g}$.

Water to make... 2 liters.

Treated sample 2 min.

No. 3 for Acid Hardening Fixing Bath:

Glacial acetic acid. $30 \mathrm{ml}$.

Water to make 2 liters.

Treated sample 30 secs.

\subsection{Fixing Baths}

Neutral Fixing Bath:

Sodium thiosulfate $\left(\mathrm{Na}_{2} \mathrm{~S}_{2} \mathrm{O}_{3} \cdot 5 \mathrm{H}_{2} \mathrm{O}\right) \ldots \ldots \ldots 245.0$ g. Water to make.............................. 1 liter.

Fixed sample 4 min.

- Nonhardening Acid Fixing Bath:

Sodium thiosulfate $\left(\mathrm{Na}_{2} \mathrm{~S}_{2} \mathrm{O}_{3} \cdot 5 \mathrm{H}_{2} \mathrm{O}\right) \ldots \ldots \ldots 240.0$ g.

Sodium bisulfite.......................... $25.0 \mathrm{~g}$.

Water to make............................ 1 liter.

Fixed sample 5 min.

Acid Hardening Fixing Bath:

Sodium thiosulfate $\left(\mathrm{Na}_{2} \mathrm{~S}_{2} \mathrm{O}_{3} \cdot 5 \mathrm{H}_{2} \mathrm{O}\right) \ldots \ldots \ldots 300.0 \mathrm{~g}$.

Sodium sulfite.............................. $10.0 \mathrm{~g}$.

Glacial acetic acid......................... $10 \mathrm{ml}$.

Boric acid............................. $5.0 \mathrm{~g}$.

Potassium aluminum sulfate............... $10.0 \mathrm{~g}$.

Water to make.............................. 1 liter.

Fixed sample $4 \mathrm{~min}$.

\subsection{Chemical Specifications}

All of the solutions were made up with distilled water. The following chemicals were of reagent quality meeting ACS specifications: sodium sulfite, acetic acid, boric acid, potassium bromide, and potassium iodide. The monomethyl $p$-aminophenol sulfate, hydroquinone, sodium carbonate, sodium thiosulfate, and potassium aluminum sulfate conformed to the USA Standards Institute Specifications for Photographic Grade Chemicals. The sodium bisulfite was analytical reagent grade.

\section{References}

[1] R. W. Henn and D. G. Wiest, Microscopic spots in processed microfilm: their nature and prevention, Phot. Sci. Eng. 7, 253 (1963).

[2] C. S. McCamy, Inspection of processed photographic record films for aging blemishes, National Bureau of Standards Handbook 96 (U.S. Government Printing Office, Washington, D.C., 1964).

[3] C. S. McCamy and C. I. Pope, Summary of current research on archival microfilm, National Bureau of Standards Technical Note 261 (U.S. Government Printing Office, Washington, D.C., 1965).

[4] C. S. McCamy and C. I. Pope, Current research on preservation of archival records on silver-gelatin type microfilm in roll form, J. Res. NBS 69A (Phys, and Chem.) No. 5, 385 (1965).

[5] C. E. K. Mees, The Theory of the Photographic Process, p. 103 , (The Macmillan Co., New York, N.Y., 1954).

[6] Charles N. Durfor and Edith Becker, Public Water Supplies of the 100 Largest Cities in the United States, 1962, U.S. Geological Survey Water-Supply Paper 1812 (U.S. Government Printing Office, Washington, D.C.).

[7] W. A. Taylor and F. R. McCrumb, Modern $p \mathrm{H}$ and Chlorine Control, p. 42 (W. A. Taylor \& Co., Baltimore, Md. 1931).

[8] William J. Ryan, Water Treatment and Purification, p. 197 (McGraw-Hill Book Co., New York, N.Y., 1946).

[9] J. R. Partington, A Text-Book of Inorganic Chemistry, pp. 334 and 804 (The Macmillan and Co., Limited, London, 1933).

[10] J. W. Laist, Copper, Silver and Gold, Vol. II, Comprehensive Inorganic Chemistry, p. 155 (D. Van Nostrad Company, Inc., New York, N.Y. 1954).

[11] W. M. Latimer and J. H. Hildebrand, Reference Book of Inorganic Chemistry, p. 24 (The Macmillan Co., New York, N.Y. 1935).

[12] C. I. Pope, Formation of silver sulfide in the photographic image during fixation, J. Res. NBS 64C (Engr. and Instr.) No. 1, 65 (1960).

[13] The Condensed Chemical Dictionary, 3d edition, p. 592 (Reinhold Publishing Corp., N.Y., 1942).

[14] R. W. Henn, D. G. W'iest, and B. D. Mack, Microscopic spots in processed microfilm: The effect of iodide, Photo. Sci. Eng. 9, 167 (1965).

[15] Eugene Sawicki, T. R. Hauser, and Sylvester McPherson, Spectrophotometric determination of formaldehyde and formaldehyde-releasing compounds with chromotropic acid, 6-amino-1-naphthol-3-sulfonic acid (J acid), and 6-anilino-1naphthol-3-sulphonic acid (phenyl J acid), Anal. Chem. 34, $1460(1962)$

(Paper 72A3-499) 